\title{
Apontamentos sobre a relevância da mídia para o contexto amplo da infância, adolescência e juventude
}

\author{
Guilherme Canela de Souza Godoi*
}

\begin{abstract}
Resumo
Este artigo pretende discutir as caracteristicas normativas (o dever ser) e efetivas (o ser) da cobertura noticiosa das chamadas políticas públicas sociais direcionadas prioritariamente ao público infanto-juvenil. A intenção é apontar as possibilidades de avanço nesta cobertura, os desafios e as dificuldades ainda enfrentados pelos jornalistas ao se enveredarem por esta temática. Como recorte, problematizaremos dados obtidos a partir de pesquisas coordenadas por nós no ámbito da Agência de Noticias dos Direitos da Infância (ANDI), ao longo dos últimos 6 anos. Tais investigaçōes analisaram 0 trabalho de, aproximadamente, 50 jornais em relação a questōes relevantes para a chamada área social, com especial atençăo para as questões da infância e da adolescência.
\end{abstract}

Palavras-chave: Jornalismo, Politicas Públicas, Agenda-setting; Infáncia \& Adolescência; ANDI

\begin{abstract}
This article addresses the normative aspects (sollen) and objective aspects (sein) of the press media coverage concerning children and youngsters when social policy is its focus. The purposes of this article are to circumscribe ways to advance this coverage; undersfand now existing challenges; and bound difficulties still faced by journalists which make their way toward social issues. The focal point will be data previously gathered along Nows Agency for Children's Rights' (ANDI) research projects, which I personally have coordinated since the last six years. These investigations analyzed press media articles published in nearly 50 Brazilian newspapers concerning social issues, specially childhood and adolescence matters.
\end{abstract}

Key words: Journalism; Social Policies; Agenda setting; Childhood and Adolescence; ANDI

- Mestre em Ciéncia Politica (USP). Coordenador de Relaçőes Académicas da Agência de Noticias dos Direitos da Infảncia, é tambèm responsável pelas pesquisas da Organizaçảo. 


\section{Introdução}

Constitui-se em tarefa um tanto quando inglória analisar o tratamento editorial dispensado pelos meios de comunicação impressos ao universo de grandes conjuntos populacionais, como é o caso das crianças e adolescentes. O que enfocar? Quais os recortes mais pertinentes?

Assumindo a premissa de que devemos falar de múltiplas infâncias, adolescências e juventudes, com suas distintas configurações de gênero, raça/etnia, orientação sexual, localidade de residência, renda, interesses, com suas igualmente diversificadas influências históricas, sociais e culturais, muitos seriam os recortes passiveis de atenção dos pesquisadores, dos formuladores de políticas públicas e, por conseguinte, das redaç̃es.

Em face deste cenário, duas saídas seriam possíveis: 1) focalizar um recorte temático específico e suas variaçðes; 2 ) concentrar-se em um eixo condutor que perpasse as numerosas esferas de interesse.

Nossa proposta de reflexão sobre o papel dos meios de comunicação noticiosos caminha fortemente pela direção número dois. $O$ que pretendemos, na sequência, é apresentar alguns apontamentos preliminares subtraídos de uma série de pesquisas sobre os meios de comunicação, conduzidas pela Agência de Notícias dos Direitos da Infância sob nossa coordenação. Estes apontamentos buscam responder a duas questões 68 básicas: quais são os temas que os meios noticiosos colocam em evidência quando se centralizam na população infanto-juvenil e como esta cobertura se dá, ao se considerar como eixo condutor a discussão ao redor das Políticas Públicas.

Ao mesmo tempo em que sinalizamos a dificuldade de se abordar um complexo conjunto populacional, também não é simples a tarefa de correlacioná-lo com o campo da comunicação. Muitas são as abordagens importantes a serem discutidas no ambiente comunicacional - também extremamente vasto - quando estamos falando de crianças, adolescentes e jovens.

Cabe-nos, portanto, definir sobre quais ângulos restringiremos nossa análise da relação entre o universo infanto-juvenil e a mídia:

Uma série de abordagens possíveis busca compreender a criança, o adolescente e o jovem como receptores de produtos midiáticos. Tanto como possíveis consumidores, quanto como sujeitos de uma interação educativa com os meios, o efeito da mensagem midiática é o ponto focal dos estudos desenvolvidos. Já um outro grupo de possibilidades se concentra nestes públicos como produtores de conteúdos midiáticos ou como sujeitos ativos no processo comunicacional. Tal abordagem está presente na constituição de Conselhos Editoriais Jovens, influenciando na condução dos veículos; assim como na produção de conteúdo em veículos 
comunitários (e.g. Cala Boca já Morreu), dentro dos espaços escolares ou através da Internet.

Por fìm, infância, adolescência e juventude podem figurar como conteúdo da comunicação. A mensagem, informativa e de entretenimento, pode ser construída não somente para crianças, adolescentes e jovens, mas sobre crianças, adolescentes e jovens. $\dot{E}$ justamente nesse ponto que temos nosso foco principal de interesse: qual a importância de se falar sobre esses atores no âmbito do jornalismo?

Não são poucos os argumentos para compor uma resposta a este questionamento. Desde uma perspectiva legal e de direitos poderíamos salientar que tanto a Convenção Internacional dos Direitos da Criança, da qual todos os paises (exceto os Estados Unidos) são signatários, quanto a legislação brasileira consideram a criança e o adolescente como "Prioridade Absoluta". Se o Estado (governo e sociedade) acordam que este recorte etário merece prioridade absoluta, é tarefa da mídia, enquanto controladora social, verificar se os meios necessários estão sendo perseguidos e implementados para assegurar os direitos desta população.

Historicamente, podemos argumentar que os direitos de crianças, adolescentes e jovens, no mundo todo, além de, até hoje, estarem sendo sistematicamente desrespeitados na prática, foram reconhecidos apenas muito recentemente. A Convenção Internacional é de 1989, enquanto a legislação brasileira de 1990. Isto quando falamos da população com até 18 anos, faixa abarcada pelo ECA; os demais cidadãos enquadrados na categoria jovem acabam por, via de regra, não receberem um tratamento específico por parte da legislação, o que, a priori, não é, necessariamente, bom ou ruim. Neste sentido, um passivo tão evidente de violações demanda uma atenção redobrada dos sistemas de responsabilização do Estado, do Governo, da Sociedade e da Família, dentre os quais a mídia aparece em posição de destaque.

Biológica e psicologicamente, poderíamos apresentar um semnúmero de estudos acerca da condição especial de indivíduos em formação a qual se aplica a meninos e meninas, o que também requer uma abordagem, informativa e de entretenimento, diferenciada.

Não obstante, neste momento nos interessam os aspectos sociológicos e políticos. Por que o jornalismo não estaria cumprindo a contento seu trabalho enfocando direitos humanos em geral, populaçбes vitimizadas em geral? Por que esta necessidade de intensificar o recorte da infância, adolescência e juventude?

De acordo com o Relatório da Situação da Infância e Adolescência Brasileiras (2003), do Unicef, o Brasil conta com 61 milhões de crianças e adolescentes: 23,1 milhões têm de 0 a 6 anos da idade; 27,2 milhões, de 7 a 14 anos; e 10,7,milhões, de 15 a 17 anos. Ou seja, crianças e adolescentes representam cerca de $1 / 3$ da população nacional. Os dados do Censo 2000 
apontam, por sua vez, que temos 34 milhões de jovens ( 15 a 24 anos), perfazendo $20 \%$ da população brasileira, naquele ano.

Para além de sua pujante representatividade demográfica, os indicadores sócio-econômicos mostram uma outra força, desta vez negativa: $33,2 \%$ das crianças e adolescentes possuem mães com baixa ou nenhuma escolaridade; $44,96 \%$ são pobres; $17,32 \%$ não têm acesso à água potável; $18,72 \%$ não possuem nenhum tipo de depósito de esgoto e $8,28 \%$ trabalham. o recorte para a juventude, não é mais animador, ao contrário. São altíssimas as taxas de homicídio para a população jovem, o que leva SOARES (2004:130) a falar em "verdadeiro genocídio". Entre os jovens com 15 a 19 anos, a taxa de homicídio por 100.000 habitantes é de 42,7 , número que sobe para 67,7 entre o grupo de 20 a 24 anos, valor mais elevado entre todas as faixas etárias. Há diferenças entre os próprios grupos jovens; estas taxas são ainda mais significativas para garotos negros e pobres. A taxa de homicídios entre a população jovem parda e negra, segundo levantamento de WAISELFISH (2005:56) é 74,0\% superior a da população jovem branca.

Encontramos dados sinalizadores de desigualdades e sérios problemas sociais também em outras áreas: o Índice de Desenvolvimento Juvenil, indicador que leva em consideração temas como educação, saúde e renda, é fortemente dispar entre as Unidades da Federação. Enquanto em Santa Catarina (primeiro colocado) temos um índice global de 0,673 , em 70 Alagoas (último colocado) ele é de 0,337 (UNESCO, 2004:47).

Além disso, segundo a pesquisa Perfil da Juventude Brasileira, $42 \%$ dos jovens brasileiros, não atingiram o ensino médio, etapa adequada para a idade; coincidentemente, $42 \%$ vivem em famílias com renda inferior a 2 salários mínimos, número que salta para $62 \%$ na Região Nordeste; $31 \%$ das jovens entrevistadas pela pesquisa já têm filhos, sendo que $47 \%$ destas disseram ter tido o primeiro filho antes dos 18 anos.

Esta pequena amostra de dados salienta que parcela significativa do "problema social brasileiro" tem endereço bastante bem definido: a infância, a adolescência e a juventude. Para além do fato de que a carga negativa se intensifica se olharmos os recortes de gênero, raça/etnia, deficiência.

Portanto, não é possivel falar em cobertura adequada da "questão social" no Brasil sem olhar atenta e consistentemente para as características das crianças, adolescentes e jovens brasileiros, suas especificidades, seus direitos e as demandas por políticas públicas particulares a esta faixa etária. Desta forma, analisar a qualidade do jornalismo brasileiro no tratamento editorial dispensado a ampla área social implica em averiguar a quantas anda a cobertura acerca das populações foco deste artigo. 


\section{A complicada definição de adolescência e juventude}

Propositalmente, caminhamos até este momento sem explicitarmos uma definição de adolescência e juventude. Há inúmeros complicadores' nesta empreitada, assim como posições não convergentes dos especialistas no assunto. Assim, não é nosso propósito nos estendermos nestas celeumas.

Gostariamos, entretanto, de, telegraficamente, assinalar os seguintes pontos para o direcionamento da discussão:

1) Estamos, para efeitos de dados, olhando para um conceito demográfico/legal de adolescência e juventude. Por infância e adolescência estamos focalizando conceito definido pelo ECA, $(0$ a 12 anos incompletos e 12 a 18 anos incompletos, respectivamente) e para juventude aquele definido pela Assembléia Geral das Nações Unidades, em 1985, por ocasião do Ano da Juventude (15 a 24 anos); 2) Entretanto, entendemos as limitações deste tipo de definição, bem como os riscos da associação etária com outras linhas conceituais de compreensão da adolescência e juventude;

3) Os riscos residem no correlacionamento com visões naturalizantes destes públicos. Esta aliança, não raro, pode resultar no entendimento destas populações como um "intervalo de transição", como algo que passa, como uma "sala de espera" do mundo adulto, o que, por certo, acaba por gerar impactos nas decisøes de alocação de recursos para este conjunto populacional (UNESCO, 2004:81).

4) Assim sendo, compartilhamos de uma definição sócio-histórica de adolescentes e jovens, ou seja, aquela que leva em consideração o ambiente cultural, social, político, histórico nos quais garotos e garotas estão inseridos; visão que, necessariamente, levará a múltiplas definições do que seja ser adolescente ou jovem.

Neste contexto, os dados das pesquisas da ANDI, na imensa maioria dos casos, referem-se à população com 0 a 18 anos, em virtude dos objetivos últimos da Agência que tem por missão focalizar a infância e a adolescência em suas ações. Não obstante, sempre que possível incluímos a idéia de juventude em nossas investigações e estaremos nos valendo também destas informações nas páginas seguintes.

\section{Os temas da Mídia Impressa: a concepção midiática do contexto infanto-juvenil}

Existem dois grandes segmentos da midia impressa que importam na discussão sobre o universo infanto-juvenil: a chamada grande mídia, que é 
consumida pelos tomadores de decisðes e formadores de opinião; e a mídia jovem, composta por veículos e/ou suplementos especiais encartados nos jornais, consumida, fundamentalmente, por adolescentes das classes médi$a^{2}$, os quais, portanto, acabam por exercer uma produção jornalística de preocupações mais limitadas, ou seja, o que interessa é o diálogo com o público-alvo e não uma potencial influência na agenda das políticas públicas e no controle social das mesmas.

Portanto, de um lado, a análise da cobertura da grande mídia permite verificar o potencial impacto das discussões na agenda pública acerca dos temas pertinentes a nosso público alvo, enquanto a análise da mídia jovem ocupa-se mais em entender quais são os conteúdos diretamente transmitidos a um nicho populacional dentro do vasto espectro da adolescência e juventude.

$\mathrm{Na}$ seara do monitoramento de grande mídia realizado pela ANDI, nota-se que os 60 diários analisados em 2004 ofereceram um amplo espaço à discussão dos temas pertinentes ao universo da infância e adolescência: foram cerca de 160.000 matérias jornalisticas. Destas, $77 \%$ fizeram referência explícita à infância, $39 \%$ à adolescência, e $32 \%$ não fizeram referência a nenhuma das faixas etárias ${ }^{3}$.

Há, ao contrário do que ocorre com todo o universo de textos sobre infância e adolescência, uma forte concentração no tema Violência: o assunto é o mais abordado quando temos uma referência específica à 72 adolescência. Enquanto no agregado geral de textos analisados, o tema Violência aparece como o segundo mais abordado (com 13,97\%), no recorte específico "adolescência" ele passa a ser o primeiro, com $21,5 \%$. Isto sem adicionarmos o tema violência sexual (6\%), contabilizado de maneira separada.

Os dados que apresentamos no início deste paper, sustentam, a princípio, a pertinência desta configuração da cobertura midiática. Não obstante, é preciso salientar dois aspectos: 1) de um lado, a despeito das taxas de homicídio envolvendo a população adolescente e jovem, faz-se necessário definir se este é o principal tema referente a esta faixa etária; 2) em sendo, é necessário verificar a qualidade desta mesma cobertura.

Veja-se que, enquanto os jornais optam por colocar em evidência material sobre Violência quando o foco é a adolescência, não possuem a mesma atitude quando estamos falando sobre o conjunto da cobertura sobre infância e adolescência: $22,53 \%$ do total geral de textos têm a educação como o principal assunto discutido, constituindo-se no tema mais coberto pela mídia impressa brasileira, quando o enfoque é a infância e a adolescência, desde 1998.

Por conseguinte, cabe a indagação: deveria ser a Violência o principal tema abordado quando adolescência e juventude estão na pauta? Os dados apontam que há sérias lacunas em outras áreas, Educação especi- 
almente. A defasagem idade-série é um dos principais problemas a serem enfrentados quando estamos nos remetendo à população infanto-juvenil, em particular. Ademais, a não garantia de um conjunto de direitos, inclusive o direito à educação de qualidade, pode ser uma das causalidades das elevadas taxas de violência envolvendo adolescentes e jovens.

Assumindo, sem embargo, a posição dos veículos impressos de abordar o tema Violência prioritariamente (quando a adolescência está centralmente referida), cabe o nosso segundo questionamento: como estão fazendo? Por certo, segundo o que assinalamos, a discussão sobre violência é pertinente, entretanto, não é qualquer conteúdo veiculado que gerará os impactos almejados - melhoria das políticas públicas c maior garantia dos direitos. Os dados produzidos pela ANDI na pesquisa Balas Perdidas: um olhar sobre o comportamento da imprensa brasileira quando a criança $e$ o adolescente estão na pauta da Violência evidenciam que a qualidade da cobertura sobre violência deixa muito a desejar. A imensa maioria dos textos $(80 \%)$ focaliza a ocorrência de crimes individualizados; não há, portanto, um enquadramento desde a ótica das politicas públicas $(4,8 \%)$. Ao mesmo tempo, a cobertura é amplamente descontextualizada: não há a apresentação de causas e soluções $(6,9 \%)$; fala-se mais do adolescente jovem como agressor (40\%) do que como vítima $(23,4 \%)$, contribuindo para o fortalecimento de um mito de periculosidade exacerbada desta faixa etária; a polícia é a fonte mais ouvida pelos jornalistas $(25,7 \%)$, o que por si só não constituiria em um problema, não fosse a baixa procura a outros atores relevantes, como especialistas, os demais órgãos estatais e do sistema de garantia de direitos; não há especificação de recortes de raça/etnia, gênero, menção à legislação ou estatisticas de maneira significativa, todos eles seriam elementos contextualizadores da cobertura.

A configuração, quantitativa e qualitativa, da cobertura sobre violência é altamente criticada por adolescentes e jovens que tomaram parte de grupos focais realizados pela ANDI. Para eles, o excesso de crimes nos jornais televisivos e impressos os afasta deste tipo de programação: "de violência já basta a realidade", ouvimos em diversas cidades. Mais grave do que isto, entretanto, seriam os estereótipos, segundo eles. A violência seria, sobretudo, identificada com os adolescentes e jovens mais pobres, não raro identificados como menores (sic), enquanto coberturas e posturas mais positivas seriam associadas aos jovens de classe média. Muitos grupos caricaturaram afirmando que uma visão das classes de renda mais baixa estaria em programas como A Turma do Gueto, enquanto o oposto seria encontrado em Malhaçâo.

De fato, coberturas sobre temas como Educação e Saúde apresentam um forte viés de classes. Recente pesquisa conduzida pela ANDI sobre a Educação na Imprensa Brasileira mostrou que a cobertura é fortemente 
concentrada no ensino superior e nos vestibulares, temas que, dada a já mencionada defasagem idade-série, interessam mais às classes médias. $\mathrm{Na}$ cobertura sobre saúde, exceto para temas referentes à gravidez na adolescência, há uma forte concepção "classe média" das questões pertinentes ao universo infanto-juvenil. A pesquisa da ANDI Na sala de espera: a cobertura jornalistica sobre promoção de saúde e direitos reprodutivos na adolescência aponta que são raras as menções ao sistema público de saúde, às deficiências do SUS, ao impacto da renda nas condições de saúde; ao mesmo tempo, aparecem, com freqüência, questões sobre a saúde estética, o corpo, os exercícios físicos. Ainda sobre a cobertura envolvendo o tema Violência, observações especificas de episódios envolvendo adolescentes de classe média como vítimas apontam para uma maior propensão dos meios de comunicação em introduzirem discussões mais aprofundadas, como as de políticas públicas e legislação.

Na mídia jovem, há um cenário distinto: temas como Educação, Cultura, Atualidades, Trabalho aparecem bastante à frente da discussão sobre a violência, já tendo em conta uma declarada ojeriza dos públicos jovens com relação ao tema. A cobertura também é mais amplificada, ainda que continue discutindo pouco as políticas públicas. É preciso assinalar, apesar disso, que cerca de $60 \%$ do material destes veículos não estão se ocupando em discutir quaisquer temas de fundo, mas na apresentação de um material mais voltado às necessidades de consumo de adolescentes e 74 jovens.

Ou seja, os dados que vêm sendo coletados pela ANDI nos últimos 10 anos têm demonstrado um espaço cada vez maior dedicado aos temas pertinentes ao universo infanto-juvenil. Não nos parece equivocado afirmar que não temos mais uma questão de espaço a ser disputado nas páginas dos jornais, mas sim uma questão de qualificação deste espaço.

Esta qualificação passa, inclusive, por uma reconfiguração do próprio rol de temas cobertos pela mídia, questões centrais, como a participação política de adolescentes e jovens, por exemplo, são praticamente esquecidas pelos veículos.

Entretanto, conforme apontamos, nosso objetivo final é salientar a importância de se enquadrar as discussões desde uma ótica das Políticas Públicas. É preciso politizar as discussões sobre questões sociais, sejam elas violência, educação, saúde ou quaisquer outras. Por politizar entendemos retirá-las de uma esfera de responsabilização individual ou de nenhuma responsabilização e passá-las para uma esfera de discussão coletiva, especialmente estatal. Adicionalmente, não basta ao jornalista abordar a Política Pública enquanto sinônimo de programas e projetos específicos governamentais, especialmente, em suas fases de lançamento, numa espécie de individualização da própria cobertura das políticas públicas. É preciso ir além, entendendo como as questões pertinentes ao univer- 
so infanto-juvenil estão sendo, consistentemente ou não, abordadas como políticas que, de fato, permeiam a estrutura estatal brasileira. É o que trabalharemos na sequência.

\section{Políticas públicas: a disputa na esfera pública}

Partindo da premissa ${ }^{4}$ de que os meios de comunicação noticiosos são fundamentais no processo de informação da sociedade em geral e, em particular, dos grupos que buscam colocar seus interesses na arena política (ou esfera pública), abordaremos, nos próximos parágrafos, o papel da imprensa na instrumentalização (ou não) de uma reflexão mais consistente em relação às diferentes etapas do processo de constituição das políticas públicas com foco no público infanto-juvenil.

As próximas seções estão organizadas da seguinte maneira: na primeira parte, problematizaremos a idéia de políticas públicas, seus distintos componentes e a relação da imprensa com algumas destas características; na segunda parte, apresentaremos mais alguns dados empiricos de pesquisas que conduzimos no âmbito da ANDI, procurando ilustrar algumas das reflexðes de cunho teórico que estaremos elaborando; e, por fim, apresentaremos nossas conclusðes.

\section{$1^{\text {a }}$ Parte: Política Pública Social: do que estamos falando?}

Inicialmente, soa-nos pertinente esclarecer duas dúvidas que não seriam desprovidas de razão: por que a necessidade de explicar a palavra "política" a partir da adição do termo pública? E, na mesma linha de raciocinio: por que a insistência nas políticas públicas sociais? Năo possuem as políticas públicas características institucionais e conceituais semelhantes? Afinal, não estamos falando de um conjunto de ações estatais abarcadas numa mesma família lógico-conceitual?

Efetivamente, política não é um equivalente semântico de politica pública, nem vice-versa. Em outras linguas, como o inglês, por exemplo, há palavras não compostas para diferenciar os dois conceitos abstratos (politics para política e policy para política pública). Se é bem verdade que não é possível fazer política pública, sem fazer política, é totalmente possível fazer política sem fazer política pública. Uma decisão partidária de lançar este ou aquele candidato a determinado cargo só terá reflexo nas políticas públicas caso ele venha a ser eleito, do contrário esta decisão ficará apenas no espaço da politica (politics).

Algumas são as razões que nos levaram a concentrar nossos esforços explicativos e de pesquisa no conjunto especifico das políticas públicas, conhecido como área social. Em primeiro lugar, ao qualificarmos as 
"políticas públicas" estamos imediatamente apresentando uma de suas características mais centrais: não se pensam "políticas públicas" em geral, como bem assinala ALENCAR (2004), as políticas públicas devem, necessariamente, ser acompanhadas de um qualificador. Temos uma política pública educacional, de saúde, econômica, tributária.

Por fim, e como consequência do exposto anteriormente, enquanto outras políticas públicas acabam por ser discutidas de forma eficiente e apropriada nos meios de comunicação, no caso das políticas sociais ainda há um processo muito incipiente de avanço qualitativo por parte das comunidades jornalísticas. Enquanto é praticamente impossível a um jornalista econômico falar de taxa de juros sem mencionar metas inflacionárias (dado que são dois temas umbilicalmente correlacionados), é muito factível a um colega da área social falar sobre abuso sexual sem associar a temática a questões de gênero, mesmo que estas estejam, também, inerentemente conectadas.

\section{A) Caracteristicas das Politicas Públicas: o Processo}

Uma política pública não pode ser resumida ao ponto aparentemente culminante de sua implementação, qual seja, o momento em que, por exemplo, os diferentes beneficiários recebem o bem, serviço ou ação inicialmente propostos. Assim, ainda que uma política pública para o

76 tratamento e cuidado de adolescentes abusadas sexualmente possa ser confundida com o instante em que a primeira adolescente é atendida em uma clínica pública de assistência psicológica recém-inaugurada, é preciso compreendermos que muitas outras ações foram necessárias antes da inauguração da clínica e muitas outras serão necessárias depois do evento, para que se tenha implantado, efetivamente, uma política pública. Ou seja, este gênero das políticas possui, portanto, a propriedade dinâmica de somente poder ser caracterizado enquanto uma política pública após a efetivação de inúmeras etapas. Uma política pública não é um fenômeno estático, mas sim um processo. Em diversas destas etapas, senão em todas, a mídia tem papel central's.

Uma política pública começa a nascer durante a disputa eleitoral; neste momento (t0), diferentes propostas de intervenção na realidade são apresentadas ao eleitor que deverá escolher a que the parece mais apropriada nesta espécie de mercado de idéias. A mídia, nesse contexto, é fundamental no fornecimento de subsídios aos leitores, telespectadores, ouvintes e internautas para que possam, com a informação mais completa possível, optar entre esta e aquela proposta. Isto para não falarmos no poder de agendamento que a mídia tem em relação aos temas que serão abordados na campanha, assunto ao qual voltaremos na sequência.

$\mathrm{Na}$ fase (t1), com o fim da disputa eleitoral, cabe ao decisor eleito es- 
colher, dentre as inúmeras possibilidades de áreas, quais destinar recursos, quais elegerá como prioritárias. Nesta etapa, novamente, a midia atua com protagonismo: ou seja, segundo problematiza a teoria do agenda-setting, a mídia possui a capacidade de influenciar fortemente na posição dos temas no ranking de prioridades dos tomadores de decisão.

Escolhido um tema para atuação ${ }^{6}$, os responsáveis pela área deverão desenhar as ações a serem implementadas para a solução do problema. Neste momento (t2), novas escolhas deverão ser feitas; em geral, os problemas complexos de uma sociedade podem ser resolvidos de distintas maneiras. Diferentes ações impactam de maneira igualmente diversa os distintos grupos de interesse e, portanto, não são consensuais. Logo, ao escolher o curso de ação que deseja tomar, o governo deverá estar preparado para convencer os atores relevantes, sem o que a implementaçâo da política não é viável. Esta multiplicidade de caminhos possíveis acaba por ser ou não potencializada pela cobertura dos meios de comunicação: a apresentação de opiniões divergentes acerca de temas não consensuais colabora para a construção de políticas públicas mais plurais e para uma tomada de decisão fundamentada em um debate mais amplo e, por conseguinte, mais democrático.

Não raro, após desenhar sua política pública, o decisor deverá submetê-la a um processo ( $\mathrm{t} 3$ ) de aprovação (o qual, em geral, se dá no braço legislativo do Estado). Desde a aprovação da dotação orçamentária para as ações propostas até modificações maiores na legislação (como a aprovação de um Fundo Constitucional), muitas podem ser as formas de envolvimento do legislativo no processo de formatação das políticas públicas, não devendo seu papel ser desconsiderado pelos atores interessados na manutenção ou alteração da política inicialmente proposta.

Em se aprovando o desenho da proposta e os recursos para a execução das açðes delineadas, passa-se à fase de implementação (t4). É neste momento que a mídia exerce uma função que, historicamente, the é conferida por quase todas as vertentes ideológicas em países democráticos: a fiscalização. Fiscalização dos recursos empregados, dos processos licitatórios, do respeito ao que foi definido pelo legislativo. Tanto o processo de implementação quanto o de fiscalização envolvem muitos atores: de um lado, a burocracia governamental, os prestadores de serviço e os próprios beneficiários; de outro, os Tribunais de Contas, o Ministério Público e os grupos de interesse.

Por fim (t6), é necessário avaliar a implementação das ações propostas com a utilização de metodologias apropriadas e de avaliadores externos, nunca se esquecendo de incluir a percepção dos beneficiários das políticas (stakeholders). Veja-se que essa etapa é diferente da fiscalização da adequada aplicação dos recursos, conforme apontado na fase anterior. Uma política pode ser extremamente bem aplicada do ponto de vista legal e moral, mas 
pode ser ineficaz do ponto de vista dos resultados. Portanto, os dois processos são fundamentais para o processo de implementação das políticas públicas, o qual deveria se retroalimentar a partir da condução adequada do processo.

\section{B) Características das Politicas Públicas: Elementos Constitutivos}

Desta descrição do processo de constituição de uma determinada política pública, já saltam aos olhos alguns elementos constitutivos deste tipo de políticas, nosso intuito agora é sublinhar alguns destes elementos.

Uma característica sine qua non de uma política pública é seu caráter não excludente, ou seja, a partir do momento em que se definam as características do público a ser beneficiado por aquela política, todos aqueles que possuam estas características, partidários ou não dos tomadores de decisão, deverão ser atingidos pela medida. Entretanto, alguns públicos podem ser maiores do que outros e, efetivamente, a escolha de públicos bastante especificos tem sido uma estratégia secular de manutenção de determinado status quo. Enquanto uma política de redução de impostos sobre a cesta básica atinge milhões de brasileiros, uma política de redução de impostos de importação sobre produtos de luxo atinge algumas centenas. A capacidade de alcance da política escolhida deve estar 78 constantemente no escopo de reflexão dos jornalistas.

Escolhas de temas a serem priorizados podem ser orientadas por diversas razões, umas mais e outras menos nobres, a depender do observador. Podemos utilizar diagnósticos da real situação das áreas para intervenção (estatísticas, pesquisas), ouvir as demandas das populações que se pretende beneficiar, incluindo as posições divergentes ou o grupo político no poder que pode atender aos anseios dos grupos de interesse que o elegeram. Como o processo de informação, inclusive dos decisores, se dá em grande medida pelos meios de comunicação, aqui também eles devem assumir papel de destaque na apresentação de estatísticas e de opiniões divergentes.

$O$ desenho efetivo das políticas escolhidas pode ser otimizado e aprimorado com a observação de casos bem sucedidos (benchmarking), a coleta de informações junto aos potenciais beneficiários, 0 apoio de especialistas na temática, a definição precisa das causas e responsáveis pelos problemas que se deseja enfrentar. Novamente, a cobertura pode colaborar com o aprofundamento da reflexão prévia necessária para a melhor engenharia de uma determinada política pública.?

Outro elemento fundamental para o desempenho bem sucedido de uma política pública é o adequado tratamento da legislação envolvida. Por um lado, é importante verificar se uma política mandatória a partir da legisla- 
ção (saúde para todos, por exemplo) não está sendo negligenciada pelos tomadores de decisão; de outro, em muitos casos, a adequada formatação do marco legal (seja da lei de diretrizes orçamentárias, seja de uma emenda constitucional) é pré-requisito para a implementação eficiente de uma política pública. Ou seja, não é possivel pensarmos em uma política pública que entenda a criança e o adolescente como sujeitos de direitos, tendo como marco legal o antigo Código de Menores. Sem a aprovação e consolidação do Estatuto da Criança e do Adolescente, políticas eficientes para a área simplesmente não seriam factiveis.

Adicionalmente, as politicas públicas envolvem múltiplos atores: eleitores devem escolher a melhor proposta entre os candidatos oferecidos pelos partidos políticos; o executivo deve propor as políticas a serem implementadas, a partir da pressão dos grupos de interesse, das bases e da sociedade de maneira mais difusa; ao mesmo tempo, deve negociar com $o$ legislativo (situação e oposição) o formato das políticas que deseja implementar; políticas bem executadas demandam uma burocracia bem preparada para a implementação, sintonia com os beneficiários e uma adequada fiscalização do Ministério Público, do Legislativo, do Judiciário, da mídia e dos grupos de interesse. A adequada identificação das posições e interesses destes atores colabora para uma definição mais precisa do tipo de políticas a serem conduzidas; a mídia, certamente, é um dos atores com capacidade para veicular as posições conflitantes e convergentes.

O esboço de caracterização das políticas públicas, aqui delineado tentativamente, procurou traçar pontos sem os quais uma cobertura sobre uma determinada política será falha e inconsistente, podendo inclusive contribuir para a retroalimentação de um ciclo de desenvolvimento de políticas pouco eficientes para o atendimento dos reais problemas vivenciados dos potenciais beneficiários.

Nosso intuito é apresentar, na seqüência, uma rápida problematização dos papéis da mídia no desenvolvimento das políticas públicas sociais, ilustrando as discussões aqui tecidas com dados da cohertura sobre questões relevantes para arena social. Questões que inegavelmente poderiam ser tratadas como políticas públicas tanto pelo Estado como pela mídia, mas que, com muita frequiência, não o são.

\section{$2^{\mathrm{a}}$ Parte: Papéis e comportamentos da mídia}

\section{A) Problematização teórica e dados empiricos}

Quatro potencialidades dos meios de comunicação, historicamente analisadas pelos cientistas sociais das mais diferentes áreas, são de especial relevância para o processo de desenvolvimento das políticas públicas: sua capacidade de agendamento, de enquadramento, de construção da informação e de controle social. 
De acordo com o célebre aforismo de Bernard C. Cohen, a mídia "may not be successful much of the time in telling people what to think, but it is stunningly successful in telling its readers what to think about". O pensamento resume a idéia básica acerca da capacidade da mídia de interferir, a partir daquilo que ela publica e/ou omite, nos temas que estarão no topo da lista dos decisores. Com a rápida expansão das possíveis áreas de interferência do Estado - expansão em muito relacionada ao reconhecimento de diferentes ordens de direitos aos cidadãos e às gerações futuras - foi se tornando cada vez mais urgente a necessidade de priorizar apenas algumas das demandas que são cotidianamente colocadas na esfera pública. Mesmo os analistas mais desconfiados acerca do alcance proposto pelas teorias do agendamento hão de concordar que, dado que uma escolha será necessária e que um critério ou mais critérios de escolha deverão ser utilizados, a focalização mais intensa da mídia em determinados temas colaborará para a inclusão ou retirada de um assunto da pauta ${ }^{8}$.

Não obstante, a freqüência com que a mídia reporta determinados temas é mais um dos elementos que contam na formatação das politicas públicas. Temas que afetam, por exemplo, cotidianamente de forma direta a vida dos eleitores, acabam por serem pouco influenciados pelo volume de informações trazido pelo noticiário: por mais que a mídia insista em não cobrir saúde, os eleitores vão continuar demonstrando aos seus representantes que este é um tema central em suas vidas?

80 Assim, o entendimento da construção das politicas públicas nos parece ainda engatinhar no jornalismo brasileiro; há uma nítida separação entre a política partidária, legislativa e presidencial que ocupa, em geral, os cadernos de política dos jornais, onde a troca de ministros, as negociações com parlamentares, $\mathrm{e}$ as questóes de interesse humano envolvendo políticos profissionais têm espaço garantido, dado que todos são entendidos como elementos do que se pode chamar de política. De outro lado, nos parece igualmente bem delimitada a idéia de política econômica, que também conta com um espaço garantido nos cadernos de economia. A despeito disso, as demais políticas públicas, não raro, acabam por não serem reconhecidas como integrantes do universo cognitivo e de significados da própria Política. Ganham diferentes espaços nos jornais e são mais ou menos entendidas como políticas, a depender do jornalista que é encarregado da reportagem e das personagens que compõem o fato noticiado. Assim, a violência só passa a ser entendida como uma questão de política pública à medida que sai dos cadernos policiais, sendo, portanto, coberta por repórteres diferenciados das redações, e à medida que as personagens são membros dos executivos estaduais, municipais ou federais diretamente ocupados das politicas de segurança pública, ou na medida em que especialistas se dedicam ao tema, tratando-o como um fenômeno social, cultural e político, e até mesmo de saúde pública. De resto, o tema continua 
sendo explorado fortemente como crime que o indivíduo $x$ cometeu contra 0 individuo y. Onde está a política neste contexto?

Logo, alguns assuntos podem ou nâo ser entendidos como políticas públicas. Ou seja, o enquadramento conferido ao tema pode influenciar distintas etapas do processo de construção de significados sobre políticas públicas pelos diferentes atores envolvidos.

Conforme salientamos, diferentes fases no desenvolvimento de uma política pública demandam 0 conhecimento de distintos níveis de informação (estatísticas, legislações, posições de atores diversos, melhores práticas). A mídia é um potencial investigador $\mathrm{e}$ fornecedor destas informações, inclusive conferindo voz a fontes alternativas e contestadoras de dados oficiais. Papel este, em geral, pouco desempenhado.

Por fim, toda política pública, em regimes democráticos, supõe que os atores por elas responsáveis devem demonstrar algum grau de accountability. Entretanto, esta característica é tão mais crivel quanto mais externos ao processo forem os atores responsáveis pelo controle da mesma. A imprensa, desde as discussões travadas pelos Federalistas para a constituição da democracia norte-americana, é entendida como uma das principais instituições de controle social dos governos eleitos. Neste sentido, o acompanhamento não apenas do lançamento oficial de projetos, mas de sua continuidade, da idoneidade em sua execução e de seus resultados é (ou deveria ser) tarefa a ser conduzida com afinco pelos profissionais da noticia ${ }^{10}$.

\section{B) Alguns dados empiricos"}

Dois dados advindos do monitoramento diário que a Agência de Notícias dos Direitos da Infância realizou entre 1996 e 2004 junto ao material jornalístico veiculado por 45 jornais de 25 unidades da federação ${ }^{12}$ são expressivos da potencialidade de interferência da mídia no processo de constituição das políticas públicas: o crescimento percentual do número de texto jornalísticos (matérias, editoriais, artigos, colunas) sobre temas pertinentes ao universo infanto-juvenil (educação, saúde, violência e outros 22 temas) veiculados entre 1996 e 2004 foi de $1.149 \%$, passando de 10.540 textos no primeiro ano para 131.617 no último ano da pesquisa, para os mesmos 45 jornais. $\dot{E}$ absolutamente incontcstávcl que um espaço sem precedentes na imprensa brasileira foi conferido à pauta da infância e da adolescência. Além disso, em 1996, 66,71\% das fontes eram conectadas institucionalmente aos poderes públicos governamentais, enquanto $33,29 \%$ eram advindas das organizações da sociedade civil. Já em 2003, o quadro se inverte, estando $35,83 \%$ ligadas ao poder público e $44,80 \%$ às organizações da sociedade civil. Tal resultado indica que além das temáticas pertinentes à infância e à adolescência terem adquirido uma presença muito mais consis- 
tente na pauta dos veículos (e, espera-se, na esfera pública de discussões), elas passaram a ser apresentadas, discutidas e demandadas por um número diversificado de atores, para além das tradicionais fontes oficiais ${ }^{13}$. A maioria dos indicadores evidencia uma melhora na qualidade de vida de crianças e adolescentes brasileiros no período em análise (queda na mortalidade infantil, na taxa de trabalhadores infantis, aumento na taxa de escolarização e no volume orçamentário destinado a estas populações). Efetivamente, outro tipo de estudo deve ser conduzido para a verificar se foi a mídia que pautou as mudanças ou as mudanças pautaram a midia ${ }^{14}$; sem embargo, uma elevada cobertura da mídia sem reflexo algum na realidade das políticas públicas seria prova cabal da inoperância da teoria do agendamento, o que não ocorreu. ${ }^{35}$ De mais a mais, a pauta diversificada permite a um número maior de atores a interação com os debates pertinentes para a esfera da infância e da adolescência e, portanto, um enriquecimento dos grupos que tentam influenciar no processo de definição das políticas públicas.

\section{Conclusão}

Os dados apresentados permitem traçar a hipótese, a ser averiguada no futuro, de que o avanço da mídia na cobertura social acaba por colaborar com apenas algumas etapas do processo de formulação de politicas públicas para área: notoriamente, a etapa de escolha dos temas.

Entretanto, todos os demais elementos para a construção de políticas públicas mais qualificadas e mais eficientes são fortemente negligenciados por parcela significativa da cobertura. Ou seja, ao enquadrar de maneira enviesada e deficitária o que poderia ser uma cobertura de políticas públicas sociais, a mídia acaba por enfraquecer a suas próprias capacidades de agendamento, fornecedora de informações e controladora social. O entendimento da complexidade das políticas públicas, portanto, é central para o avanço da cobertura, dado que a hipótese mais provável para explicar o atual estágio não é a do maniqueísmo ou qualquer outra teoria da conspiração, mas a de desconhecimento técnico por parte dos profissionais de mídia, ocasionado pelo descaso dos veículos com a estruturação adequada de uma área de cobertura das políticas públicas sociais. Ademais, vale assinalar que este potencial substituição das chamadas hard news pelo seu oposto não é apenas um fenômeno nacional (cf., e.g., PATTERSON, 2000).

É, adicionalmente, fundamental retomarmos a idéia de correta focalização das políticas públicas sociais: a não percepção, por parte dos decision makers e de controladores sociais, como a mídia, de que em países como Brasil fazer política pública na arena social é fazer, em grande medida, política pública para infância, adolescência e juventude, pode trazer como conseqüências imediatas resultados práticos pouco significativos na redu- 
ção da pobreza ou dos índices de violência e, logo, desperdício de recursos públicos.

Neste sentido, avaliar a cobertura jornalística sobre a infância, adolescência e juventude e políticas públicas é um ponto central no entendimento do correto (ou inadequado) agendamento da discussão social no Brasil.

Entretanto, os dados apontam que já há caminhos mais consistentes percorridos na análise especifica sobre temas da infância, aí a cobertura já estaria mais consistente do que quando olhamos especificamente para a infância, a adolescência e a juventude. Problemas adicionais surgem neste recorte: como uma concentração muito evidente em uma cobertura individualizada e em dicotomias mais significativas entre 0 mundo das classes mais abastadas e das menos favorecidas.

É preciso uma guinada e uma guinada que leve em consideração a voz de crianças, adolescentes e jovens de todas as regiões do pais.

\section{Referências bibliográficas}

AGÊNCIA DE NOTICIAS DOS DIREITOS DA INFÂNCIA. Imprensa, infância e desenvolvimento humano. Brasilia, 2004. No prelo.

AGÊNCIA DE NOTÍCIAS DOS DIREITOS DA INFÂNCIA. Balas perdidas: um oihar sobre o comportamento da imprensa brasileira quando a criança e o adolescente estão na pauta da violência. Brasilia: ANDI, 2001.

AGÊNCIA DE NOTÍCIAS DOS DIREITOS DA INFÂNCIA. A educação na imprensa brasileira: responsabilidade e qualidade da informação. Brasília: ANDI, 2005.

AGÊNCIA DE NOTÍCIAS DOS DIREITOS DA INFÂNCIA. Na sala de espera: a cobertura jornalística sobre promoção de saúde e direitos reprodutivos na adolescência. São Paulo: Cortez, 2006.

ALENCAR, R. P. Políticas públicas e jornalismo para a promoção do desenvolvimento humano. São Paulo, 2004. p. 1-23. MIMEO.

COSTA, J. F. Perspectivas da juventude na sociedade de Mercado. In: NOVAES, R. e VANNUCCHI, P. (Orgs.). Juventude e sociedade: trabalho, educação, cultura e participação. São Paulo: Ed. Fundação Perseu Abramo, 2004. p. 75-88.

IYENGAR, S. Television news and citizens explanations of national affairs. In: GRABER, D. A. Media power in politics. 2. ed. Washington: Congressional Quarterly Inc, 1990.p. 124-135. 
KEHL, M. R. A juventude como sintoma da cultura. In: NOVAES, R. e VANNUCCHI, P. (Orgs.). Juventude e Sociedade: trabalho, educação, cultura e participação. São Paulo: Ed. Fundação Perseu Abramo, 2004 p. 89-114.

MARSHALL, T. H. Cidadania, classe social e status. Rio de Janeiro: Zahar, 1967.

MCCOMBS, M. E. and SHAW, D. L. The agenda-setting function of the press. In: GRABER, D. A. Media power in politics. 2. ed. Washington: Congressional Quarterly Inc, 1990. p. 73-82.

OLIVEIRA, V. C. A comunicação midiática e o Sistema Único de Saúde. In: Interface _comunicação, saúde, educação, Botucatu, v.4, n.7, p. $71-80,2000$.

RIBEIRO, R. J. Política e juventude: o que fica da energia. In: NOVAES, R. e VANNUCCHI, P. (Orgs.). Juventude e sociedade: trabalho, educação, cultura e participação. São Paulo: Ed. Fundação Perseu Abramo, 2004. p. 19-33.

PATTERSON, T. E. Doing well and doing good: how soft news and critical journalism are shrinking the news audience and weakening democracy: and what news outlets can do about it. Faculty Research Working Paper Series, RWP01-001. Cambridge: John F. Kennedy School of Government, Harvard University, 2000.

SOARES, L.E. Juventude e violência no Brasil contemporâneo. In: NOVAES, R. e VANNUCCHI, P. (Orgs.). Juventude e sociedade: trabalho, educação, cultura e participação. São Paulo: Ed. Fundação Perseu Abramo, 2004, p. 130-59.

SOROKA, S.N. Issue attributes and agenda-setting by media, the public, and policymakers in Canada. In: International for ublic pinion research, v. 14, n. 3, pp. 265-285, 2002.

UNESCO. Politicas públicos de/para/com juventudes. Brasília: Unesco, 2004.

UNICEF. Relatório da situação da infância e adolescência brasileiras. Brasilia: Unicef, 2003.

WAISELFISZ, J. J. Mapa da violência $I V$ - os jovens do Brasil: juventude, violência e cidadania. Brasilia: Unesco, IAS, SEDH, 2005. 


\section{Notas}

1 O mesmo tipo de problema parece não se dar com a infância.

${ }^{2}$ Há informações de que revistas como Capricho acabam, por diversos sistemas de trocas e circulação informais, chegando a outras camadas populacionais.

${ }^{3}$ A soma da participação de cada faixa etária não se iguala a $100 \%$, já que a variável permite marcação múltipla.

4 Evidentemente que esta premissa pode ser contestada, ponto básico da ciência de tradição popperiana. Entretanto, estamos chamando este enunciado de premissa, exatamente porque a intenção deste texto não é discutir a verificabilidade ou não do mesmo, mas sim as implicações que se seguem a partir dele.

5 Para uma proposta semelhante de sistematização das fases de desenvolvimento de uma política pública, cf. Theodoulou (Apud ALENCAR: 2004, p. 4).

${ }^{6}$ Evidentemente não há escolha de um único tema, mas de vários, o exemplo segue no singular para facilitar o raciocínio.

${ }^{7}$ Para uma discussão sobre a importância de apresentação de causas pela mídia, cf. Iyengar (1990).

${ }^{8}$ A teoria do agendamento foi inicialmente desenvolvida por McCombs e Shaw (1990).

${ }^{9}$ Para algumas condições que interferem na forma do agendamento, cf. Soroka (2002).

${ }^{10}$ Para uma análise sobre cobertura da mídia em relação às políticas de saúde, cf. Oliveria (2000).

"Os dados aqui apresentados são provenientes de extensas avaliações conduzidas por nós no âmbito da ANDI sobre temáticas relevantes para a agenda social, em geral, além de assuntos com foco exclusivo em crianças e adolescentes. Entretanto, defendemos que a averiguação das políticas para infância e adolescência é representativa das políticas sociais como um todo, dado que a maioria das decisões na arena social acaba por afetar esta faixa etária.

12 Hoje a ANDI monitora 55 jornais de todas as unidades da federação.

${ }^{13}$ Estes dados estão disponíveis em ANDI (2004).

${ }^{14}$ Para uma proposta metodológica, cf. Soroka, op. cit.

is Adicionalmente, é importante notar que mesmo que a mídia é que fosse pautada pelo governo, ainda assim lhe restaria um papel de agendamento, ao escolher que políticas governamentais cobrir e ao optar por não cobrar o desenvolvimento de políticas que não vem sendo desenvolvidas para determinadas áreas. 
